\title{
Estimation of oceanic subsurface mixing under a severe cyclonic storm using a coupled atmosphere-ocean-wave model
}

\author{
Kumar Ravi Prakash, Tanuja Nigam, and Vimlesh Pant \\ Centre for Atmospheric Sciences, Indian Institute of Technology Delhi, New Delhi-110016, India \\ Correspondence: Vimlesh Pant (vimlesh@iitd.ac.in)
}

Received: 5 October 2017 - Discussion started: 10 October 2017

Revised: 27 January 2018 - Accepted: 7 March 2018 - Published: 3 April 2018

\begin{abstract}
A coupled atmosphere-ocean-wave model was used to examine mixing in the upper-oceanic layers under the influence of a very severe cyclonic storm Phailin over the Bay of Bengal (BoB) during 10-14 October 2013. The coupled model was found to improve the sea surface temperature over the uncoupled model. Model simulations highlight the prominent role of cyclone-induced near-inertial oscillations in subsurface mixing up to the thermocline depth. The inertial mixing introduced by the cyclone played a central role in the deepening of the thermocline and mixed layer depth by 40 and $15 \mathrm{~m}$, respectively. For the first time over the BoB, a detailed analysis of inertial oscillation kinetic energy generation, propagation, and dissipation was carried out using an atmosphere-ocean-wave coupled model during a cyclone. A quantitative estimate of kinetic energy in the oceanic water column, its propagation, and its dissipation mechanisms were explained using the coupled atmosphere-ocean-wave model. The large shear generated by the inertial oscillations was found to overcome the stratification and initiate mixing at the base of the mixed layer. Greater mixing was found at the depths where the eddy kinetic diffusivity was large. The baroclinic current, holding a larger fraction of kinetic energy than the barotropic current, weakened rapidly after the passage of the cyclone. The shear induced by inertial oscillations was found to decrease rapidly with increasing depth below the thermocline. The dampening of the mixing process below the thermocline was explained through the enhanced dissipation rate of turbulent kinetic energy upon approaching the thermocline layer. The wave-current interaction and nonlinear wave-wave interaction were found to affect the process of downward mixing and cause the dissipation of inertial oscillations.
\end{abstract}

\section{Introduction}

The Bay of Bengal (BoB), a semi-enclosed basin in the northeastern Indian Ocean, consists of surplus near-surface fresh water due to large precipitation and runoff from the major river systems of the Indian subcontinent (Varkey et al., 1996; Rao and Sivakumar, 2003; Pant et al., 2015). The presence of fresh water leads to salt-stratified upper-ocean water column and the formation of a barrier layer (BL), a layer sandwiched between the bottom of the mixed layer (ML) and the top of the thermocline, in the BoB (Lukas and Lindstrom, 1991; Vinayachandran et al., 2002; Thadathil et al., 2007). The BL restricts the entrainment of colder waters from thermocline region into the mixed layer; it thereby maintains a warmer ML and sea surface temperature (SST). The warmer SST together with higher tropical cyclone heat potential (TCHP) makes the BoB one of the active regions for cyclogenesis (Suzana et al., 2007; Yanase et al., 2012; Vissa et al., 2013). The majority of tropical cyclones are generated during the pre-monsoon (April-May) and post-monsoon (October-November) seasons (Alam et al., 2003; Longshore, 2008). The number of cyclones and their intensity is highly variable on seasonal and interannual timescales. The oceanic response to the tropical cyclone depends on the stratification of the ocean. The $\mathrm{BL}$ formation in the $\mathrm{BoB}$ is associated with the strong stratification due to the peak discharge from rivers in the post-monsoon season. The intensity of the cyclone largely depends on the degree of stratification (Neetu et al., 2012; Li et al., 2013). The coupled atmosphere-ocean model was found to improve the intensity of cyclonic storms when compared to the uncoupled model over different oceanic regions (Warner et al., 2010; Zambon et al., 2014; Srinivas et al., 2016; Wu et al., 2016). Zambon et al. (2014) compared the simulations from the coupled atmosphere-ocean and un- 
coupled models and reported significant improvement in the intensity of storms in the coupled case as compared to the uncoupled case. The uncoupled atmospheric model produced large ocean-atmosphere enthalpy fluxes and stronger winds in the cyclone (Srinivas et al., 2016). When the atmospheric Weather Research and Forecasting (WRF) model interacted with the ocean model, the SST was found to be more realistic compared to the stand-alone WRF (Warner et al., 2010; Gröger et al., 2015; Jeworek et al., 2017; Ho-Hagemann et al., 2017). Wu et al. (2016) demonstrated the advantage of using a coupled model over the uncoupled model in a better simulation of typhoon Megi's intensity.

Mixing in the water column has an important role in energy and material transference. Mixing in the ocean can be introduced by the different agents such as wind, current, tide, eddy, and cyclone. Mixing due to tropical cyclones is mostly limited to the upper ocean, but the cyclone-induced internal waves can affect the subsurface mixing. Several studies have observed that the mixing in the upper-oceanic layer is introduced due to the generation of near-inertial oscillations (NIOs) during the passage of tropical cyclones (Gonella, 1971; Shay et al., 1989; Johanston et al., 2016). This mixing is responsible for the deepening of the ML and the shoaling of the thermocline (Gill, 1984). The vertical mixing caused by storm-induced NIO has a significant impact on upperocean variability (Price, 1981). The NIO are also found to be responsible for the decrease in SST along the cyclone track (Chang and Anthes, 1979; Leipper, 1967; Shay et al., 1992, 2000). This decrease in SST is caused by the entrainment of cool subsurface thermocline water from the mixed layer into the immediate overlying layer of water. This cooling of surface water is one of the reasons for the decay of cyclones (Cione and Uhlhorn, 2003). The magnitude of surface cooling differs largely depending on the degree of stratification on the right-hand side of the cyclone track (Jacob and Shay, 2003; Price, 1981).

The near-inertial process can be analyzed from the baroclinic component of currents. The vertical shear of horizontal baroclinic velocities that is interrelated with buoyancy oscillations of surface layers is utilized in various studies in order to gain an adequate understanding of the mixing associated with high-frequency oscillations, i.e., NIO (Zhang et al., 2014). The shear generated due to NIO is an important factor for the intrusion of the cold thermocline water into the ML during near-inertial scale mixing (Price et al., 1978; Shearman, 2005; Burchard and Rippeth, 2009). The alternative upwelling and downwelling features of the temperature profile are an indication of the inertial mixing. The kinetic energy bounded with these components of the current shows a rise in magnitude at the right side of a cyclone track (Price, 1981; Sanfoard et al., 1987; Jacob, 2003). This high magnitude of kinetic energy is linked to strong wind and the rotating wind vector conditions of the storm. The spatial distribution of near-inertial energy is primarily controlled by the boundary effect for inertial oscillations (Chen et al., 2017).
The NIO is found to decline with decreasing depth and vanishes in the coastal regions (Schahinger, 1988; Chen et al., 2017).

The aim of this paper is to understand and quantify the near-inertial mixing due to the very severe cyclonic storm Phailin in the BoB. Phailin developed over the BoB in the northern Indian Ocean in October 2013. The landfall of Phailin occurred on 12 October 2013 around 17:00 GMT near the Gopalpur district of Odisha state on the east coast of India. After the 1999 super cyclonic event of the Odisha coast, Phailin was the second strongest cyclonic event that made landfall on the east coast of India (Sanil Kumar and Nair, 2015). The low-pressure system developed in the north of the Andaman Sea on 7 October 2013 and was transformed into a depression on 8 October at $12^{\circ} \mathrm{N}, 96^{\circ} \mathrm{E}$. This depression was converted into a cyclonic disturbance on 9 October and further intensified while moving to the eastcentral BoB, showing a maximum wind speed of $200 \mathrm{~km} \mathrm{~h}^{-1}$ at 03:00 GMT on 11 October. Finally, landfall occurred at 17:00 GMT on 12 October. More details on the development and propagation of Phailin can be found in the literature (IMD Report, 2013; Mandal et al., 2015). The performance of the coupled atmosphere-ocean model in simulating the oceanic parameters temperature, salinity, and currents during Phailin is discussed in Prakash and Pant (2017).

Most of the past studies on oceanic mixing under cyclonic conditions were carried out using in situ measurements, which are constrained by their spatial and temporal availability. To the best of our knowledge, the present study is the first of its kind to utilize a coupled atmosphere-oceanwave model over the BoB to estimate cyclone-induced mixing, its associated energy propagation on the cyclone track, and the location of maximum surface wind stress during the period of the peak intensity of the cyclone. The study also focuses on analyzing the subsurface distribution of NIO with its vertical mixing potential. Further, the study quantifies the shear-generated mixing and the kinetic energy of the baroclinic mode of the horizontal current varying in the vertical section at a selected location during the active period of the cyclone. The dissipation rate of NIO and turbulent eddy diffusivity are quantified.

\section{Data and methodology}

\subsection{Model details}

Numerical simulations during the period of Phailin were carried out using the Coupled Ocean-Atmosphere-WaveSediment Transport (COAWST) model, described in detail by Warner et al. (2010). The COAWST modeling system couples the three-dimensional oceanic Regional Ocean Modeling System (ROMS), the atmospheric WRF model, and the wind wave generation and propagation model Simulating Waves Nearshore (SWAN). The ROMS model used for 
the study is a free-surface, primitive-equation, sigma coordinate model. ROMS is a hydrostatic ocean model that solves finite difference approximations of the Reynolds averaged Navier-Stokes equations (Chassignet et al., 2000; Haidvogel et al., 2000, 2008; Shchepetkin and McWilliams, 2005). The atmospheric model component in the COAWST is a non-hydrostatic, compressible model Advanced Research Weather Research Forecast Model (WRF-ARW), described in Skamarock et al. (2005). It has different schemes for the representation of boundary layer physics and physical parameterizations of sub-grid-scale processes. In the COAWST modeling system, appropriate modifications were made in the code of the atmospheric model component to provide an improved bottom roughness from the calculation of the bottom stress over the ocean (Warner et al., 2010). Further, the momentum equation is modified to improve the representation of surface waves. The modified equation needs the additional information of wave energy dissipation, propagation direction, wave height, and wavelength that are obtained from wave components of the COAWST model. The spectral wave model SWAN, used in the COAWST modeling system, is designed for shallow water. The wave action balance equation is solved in the wave model for both spatial and spectral spaces (Booij et al., 1999). The SWAN model used in the COAWST system includes the wave wind generation, wave breaking, wave dissipation, and nonlinear wave-current-wind interaction. The Model Coupling Toolkit (MCT) is used as a coupler in the COAWST modeling system to couple different model components (Larson et al., 2004; Jacob et al., 2005). The coupler utilizes a parallel coupled approach to facilitate the transmission and transformation of various distributed parameters among component models. The MCT coupler exchanges prognostic variables from one model to another model component as shown in Fig. 1. The WRF model receives SST from the ROMS model and supplies the zonal $\left(U_{\text {wind }}\right)$ and meridional $\left(V_{\text {wind }}\right)$ components of $10 \mathrm{~m}$ wind, atmospheric pressure $\left(P_{\text {atm }}\right)$, relative humidity (RH), cloud fraction (Cloud), precipitation (Rain), and shortwave $\left(\mathrm{Sw}_{\mathrm{rad}}\right)$ and longwave $\left(\mathrm{Lw}_{\mathrm{rad}}\right)$ radiation to the ROMS model. The SWAN model receives $U_{\text {wind }}$ and $V_{\text {wind }}$ from the WRF model and transfers significant wave height $\left(H_{\text {wave }}\right)$ and mean wavelength $\left(L_{\text {mwave }}\right)$ to the WRF model. A large number of variables are exchanged between ROMS and SWAN models. The ocean surface current components $\left(U_{\mathrm{s}}, V_{\mathrm{s}}\right)$, free-surface elevations $(\eta)$, and bathymetry (Bath) are provided for the SWAN model from the ROMS model. The wave parameters, i.e., $H_{\text {wave }}, L_{\text {mwave }}$, peak wavelength $\left(L_{\text {pwave }}\right)$, wave direction ( $\left.D_{\text {wave }}\right)$, surface wave period $\left(T_{\text {psurf }}\right)$, bottom wave period $\left(T_{\text {mbott }}\right)$, percentage wave breaking $\left(Q_{\mathrm{b}}\right)$, wave energy dissipation (DISS $\left.\mathrm{wcap}_{\mathrm{w}}\right)$, and bottom orbit velocity $\left(U_{\text {bot }}\right)$, are provided from the SWAN model to the ROMS model through the MCT coupler. Further details on the COAWST modeling system can be found in Warner et al. (2010).

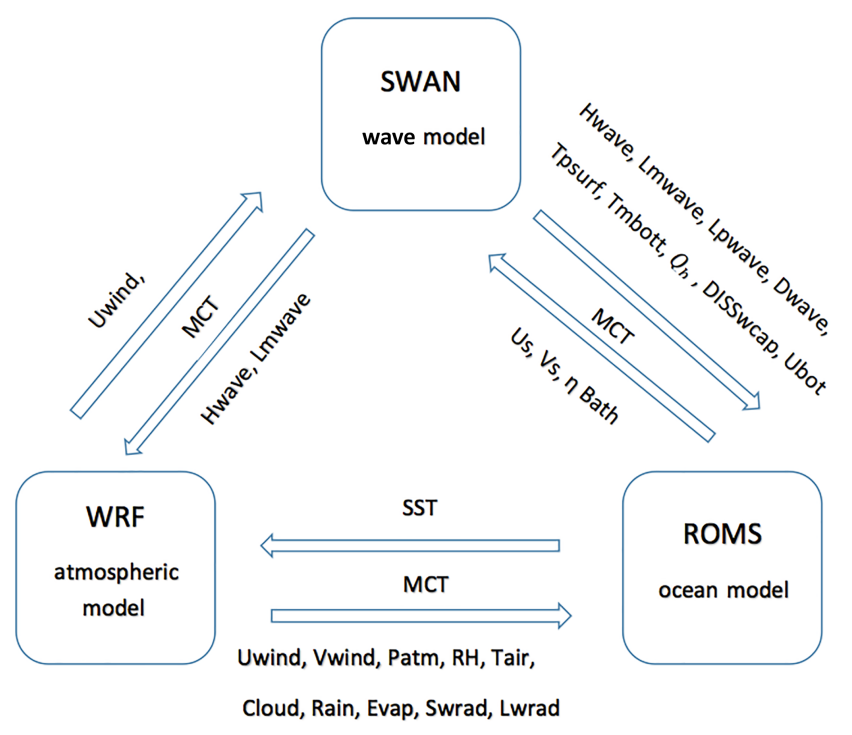

Figure 1. The block diagram shows the component models WRF, ROMS, and SWAN of the COAWST modeling system together with the variables exchanged among the models. MCT, the model coupling toolkit, is a model coupler used in the COAWST system.

\subsection{Model configuration and experiment design}

The coupled model was configured over the BoB to study Phailin during the period of 00:00 GMT 10 October00:00 GMT 15 October 2013. The setup of the COAWST modeling system used in this study included fully coupled atmosphere-ocean-wave (ROMS+WRF+SWAN) models, but sediment transport is not included. A non-hydrostatic, fully compressible atmospheric model with a terrainfollowing vertical coordinate system, WRF-ARW (version 3.7.1), was used in the COAWST configuration. The WRF model was used with $9 \mathrm{~km}$ horizontal grid resolution over the domain $65-105^{\circ} \mathrm{E}, 1-34^{\circ} \mathrm{N}$ and 30 sigma levels in the vertical. The WRF was initialized with National Centers for Environmental Prediction (NCEP) Final Analysis (FNL) data (NCEPFNL, 2000) at 00:00 GMT 10 October 2013. The lateral boundary conditions in WRF were provided at a $6 \mathrm{~h}$ interval from the FNL data. We used the parameterization schemes for calculating boundary layer processes, precipitation processes, and surface radiation fluxes. The MoninObukhov scheme of surface roughness layer parameterization (Monin and Obukhov, 1954) was activated in the model. The Rapid Radiation Transfer Model (RRTM) and cloudinteractive shortwave (SW) radiation scheme from Dudhia (1989) were used. The Yonsei University (YSU) planetary boundary layer (PBL) scheme (YSU-PBL), described by Noh et al. (2003), was used. At each time step, the calculated value of exchange coefficients and surface fluxes off the land or ocean surface by the atmospheric and land surface layer models (NOAH) was passed to the YSU-PBL. The grid-scale precipitation processes were represented by the WRF single- 
moment (WSM) six-class moisture microphysics scheme by Hong and Lim (2006). The sub-grid-scale convection and cloud detrainment were taken care of with the Kain (2004) cumulus scheme.

The terrain-following ocean model ROMS with 40 sigma levels in the vertical was used in this study. The ROMS model domain was used with zonal and meridional grid resolutions of 6 and $4 \mathrm{~km}$, respectively. This high resolution in ROMS enables us to resolve mesoscale eddies in the ocean. The vertical stretching parameters, i.e., $\theta_{\mathrm{s}}$ and $\theta_{\mathrm{b}}$ were set to 7 and 2 , respectively. The northern lateral boundary in ROMS was represented by the Indian subcontinent. The ROMS model observed open lateral boundaries in the west, east, and south in the present configuration. The initial and lateral open boundary conditions were derived from the Estimating the Circulation and Climate of the Ocean, Phase II (ECCO2) data (Menemenlis et al., 2005). The ocean bathymetry was provided by the $2 \mathrm{~min}$ gridded global relief (ETOPO2) data (National Geophysical Data Center, 2006). There was no relaxation provided for the model for any correction in the temperature, salinity, and current fields. The generic length scale (GLS) vertical mixing scheme parameterized as the K$\varepsilon$ model was used (Warner et al., 2005). Tidal boundary conditions were derived from the TPXO.7.2 (ftp://ftp.oce.orst. edu/dist/tides/Global) data, which include the phase and amplitude of the M2, S2, N2, K2, K1, O1, P1, MF, MM, M4, MS4, and MN4 tidal constituents along the east coast of India. The tidal input was interpolated from the TPXO.7.2 grid to the ROMS computational grid. The Shchepetkin boundary condition (Shchepetkin and McWilliams, 2005) for the barotropic current was used at open lateral boundaries of the domain, which allowed the free propagation of astronomical tide and wind-generated currents. The domains of the atmosphere and ocean models are shown in Fig. 2. ROMS and SWAN were configured over the common model domain shown with the shaded bathymetry data in Fig. 2. The two locations used for the time series analysis are marked with stars in Fig. 2. These two locations, one on-track and another off-track, were selected in the vicinity of the region of maximum surface cooling and wind stress during the passage of Phailin. The wave model SWAN was forced with the WRFcomputed wind field. We used 24 frequency $(0.04-1.0 \mathrm{~Hz})$ and 36 directional bands in the SWAN model. The boundary conditions for SWAN were derived from the WaveWatch III model. In the COAWST system, the free-surface elevations (ELV) and current (CUR) simulated by the ocean model ROMS are provided for the wave model SWAN. The Kirby and Chen (1998) formulation was used for the computation of currents. The surface wind applied to the SWAN model (provided by WRF) was used in the Komen et al. (1984) closure model to transfer energy from the wind to the wave field. The baroclinic time step used in the ROMS model was $5 \mathrm{~s}$. The SWAN and WRF models were used with time steps of 120 and $60 \mathrm{~s}$, respectively. The coupled modeling system allows the exchange of prognostic variables among the at-

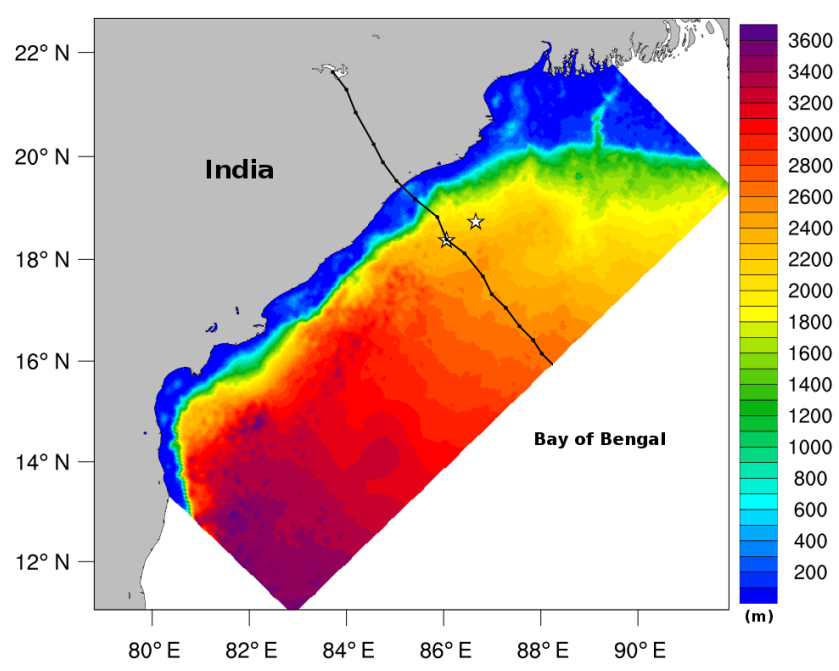

Figure 2. The COAWST model domain $\left(65-105^{\circ} \mathrm{E}, 1-34^{\circ} \mathrm{N}\right)$ overlaid with ETOPO2 bathymetry (m). Locations used for time series analysis are marked with stars.

mosphere, ocean, and wave models at every $600 \mathrm{~s}$. The SST simulation at high spatial and temporal resolutions enables accurate heat fluxes at the air-sea interface and the exchange of heat between the oceanic mixed layer and atmospheric boundary layer. The surface roughness parameter calculated in the WRF model is based on Taylor and Yelland (2001), which involved parameters from the wave model.

\subsection{Methodology}

The baroclinic current component was calculated by subtracting the barotropic component from the mean current with a resolution of $2 \mathrm{~m}$ in the vertical. The power spectrum analysis was performed on the zonal and meridional baroclinic currents along the depth section of the selected locations by using the periodogram method (Auger and Flandrin, 1995). The continuous wavelet transform using the Morlet wavelet method (Lilly and Olhede, 2012) was carried out to analyze the temporal variability in the baroclinic current at a particular level of $14 \mathrm{~m}$. The near-inertial baroclinic velocities were filtered by the Butterworth second-order scheme for the cutoff frequency range of 0.028 to $0.038 \mathrm{cycle}^{-1}$. The filtered zonal $\left(u_{\mathrm{f}}\right)$ and meridional $\left(v_{\mathrm{f}}\right)$ inertial baroclinic currents were used to calculate the inertial baroclinic kinetic energy $\left(E_{\mathrm{f}}\right)$ in $\mathrm{m}^{2} \mathrm{~s}^{-2}$ and inertial shear $\left(S_{\mathrm{f}}\right)$ following Zhang et al. (2014) and using Eq. (1).

$S_{\mathrm{f}}^{2}=\left(\frac{\partial u_{\mathrm{f}}}{\partial z}\right)^{2}+\left(\frac{\partial v_{\mathrm{f}}}{\partial z}\right)^{2}$

As the stratification is a measure of oceanic stability, the buoyancy frequency $(N)$ was calculated using Eq. (2):

$N^{2}=-\frac{g}{\rho} \frac{\partial \rho}{\partial z}$, 


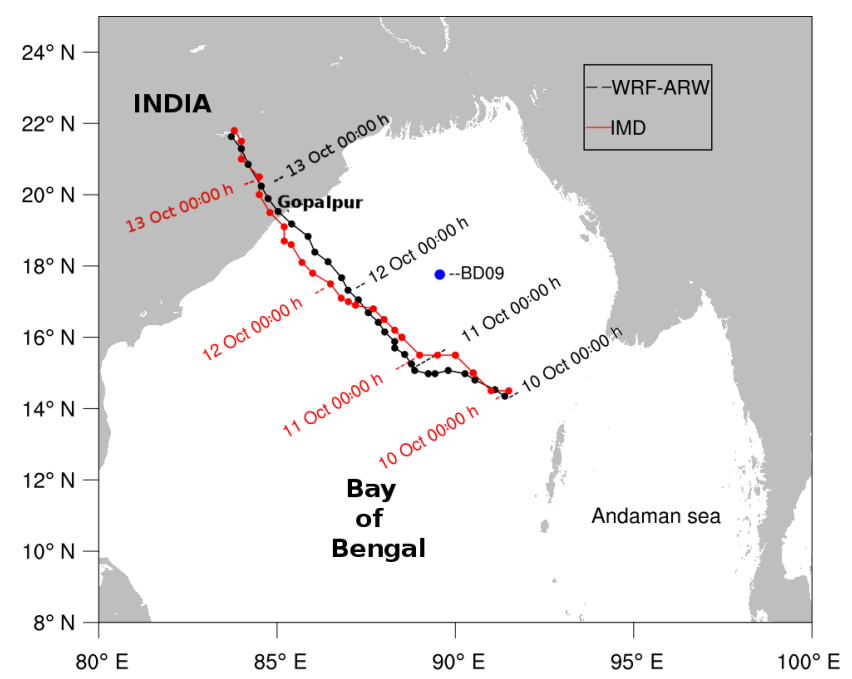

Figure 3. Tracks of Phailin simulated by the coupled model (black) and IMD reported (red). The 3-hourly positions of the center of Phailin are marked with solid circles, and the daily position at 00:00 $\mathrm{h}$ is labeled with the dates. Location of buoy BD09 is marked with a blue circle.

where $\rho$ is the density of seawater and $\mathrm{g}$ is the acceleration due to gravity.

The analysis of the generation of the inertial oscillations and their dissipation was performed on the basis of turbulent dissipation rate $(\epsilon)$ and turbulent eddy diffusivity $\left(k_{\rho}\right)$. These parameters were calculated by using the following formula (Mackinnon and Gregg, 2005; van der Lee and Umlauf, 2011; Palmer et al., 2008; Osborn, 1980):

$\varepsilon=\varepsilon_{0}\left(\frac{N}{N_{0}}\right)\left(\frac{S_{\mathrm{lf}}}{S_{0}}\right)$,

$k_{\rho}=0.2 \times\left(\frac{\varepsilon}{N^{2}}\right)$,

where $S_{\text {lf }}$ is the low shear background velocity and $N_{0}=$ $S_{0}=3$ cycle per hour and $\varepsilon_{0}=10^{-8} \mathrm{~W} \mathrm{~kg}^{-1}$.

\section{Results and discussion}

\subsection{Validation of coupled model simulations}

The WRF model-simulated track of Phailin was validated against the India Meteorological Department (IMD) reported best track of the cyclone. A comparison of the modelsimulated track with the IMD track is shown in Fig. 3. Solid circles marked on both the tracks represent the 3-hourly positions of the cyclone's center, as identified by the minimum surface pressure. The daily positions of the center of Phailin are labeled with the date. The WRF model in the coupled configuration does a fairly good job of simulating the track, translational speed, and landfall location of Phailin. The positional track error was about $40 \mathrm{~km}$ when compared

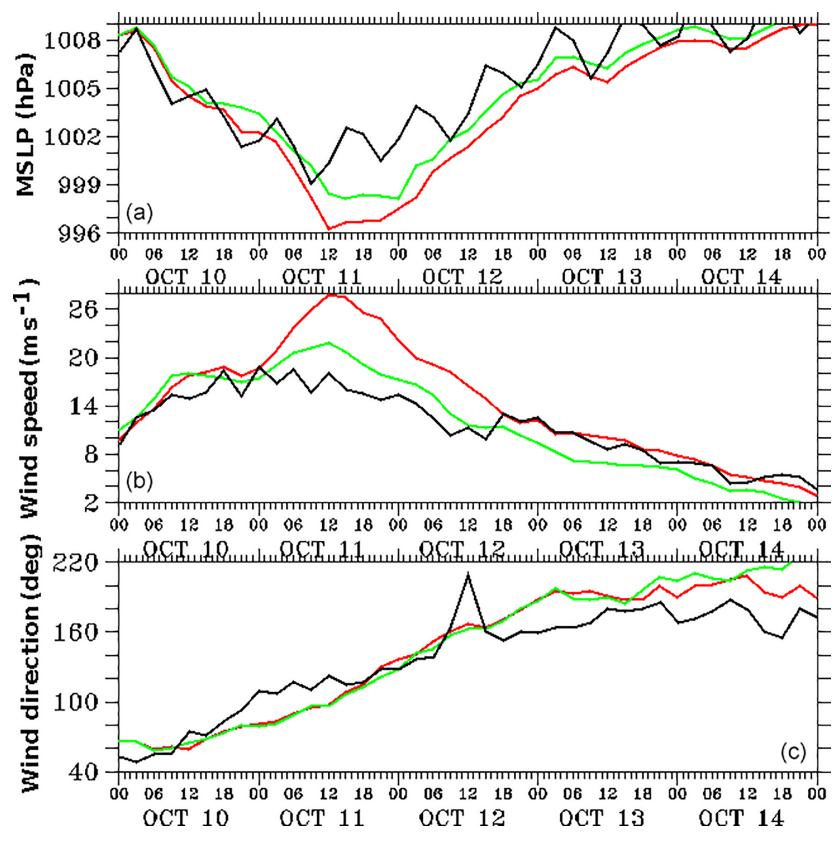

Figure 4. Comparison of coupled model (green), stand-alone WRF model (red), and observations from a buoy BD09 (black) for the (a) mean sea level pressure $(\mathrm{hPa}),(\mathbf{b})$ wind speed $\left(\mathrm{m} \mathrm{s}^{-1}\right)$, and $(\mathbf{c})$ wind direction (degree).

to the IMD track of Phailin. The stand-alone WRF model (not shown here) was found to simulate Phailin's track in an almost identical way to the WRF in the coupled configuration. However, the intensity (surface wind speed) in the WRF stand-alone model was higher compared to the coupled model. Figure 4 shows the comparison of stand-alone and coupled WRF model-simulated mean sea level pressure (MSLP), wind speed, and wind direction at a buoy (BD09) location (marked with a blue circle in Fig. 3). It can be inferred from the figure that stand-alone WRF simulated a larger pressure drop and higher wind speed compared to buoy measurements. In addition to the cyclone-induced pressure drop during 10-12 October, the semidiurnal variations in MSLP were observed in the buoy measurements. These semidiurnal variations in MSLP, primarily due to the radiational forcing (Pugh, 1987), were not captured by the model over the cyclone-influenced region. The WRF in coupled model configuration shows better performance in simulating the surface wind speed and pressure during Phailin. The exchange of wave parameters with the WRF model in the coupled configuration provides realistic sea surface roughness that resulted in the improvement of surface wind speed.

The SST simulated by the ROMS model in coupled and stand-alone configurations was validated against the Advanced Very High Resolution Radiometer (AVHRR) satellite data on each day for the period of Phailin's passage over the BoB. The stand-alone WRF-simulated parameters were used to provide surface boundary conditions in the stand- 


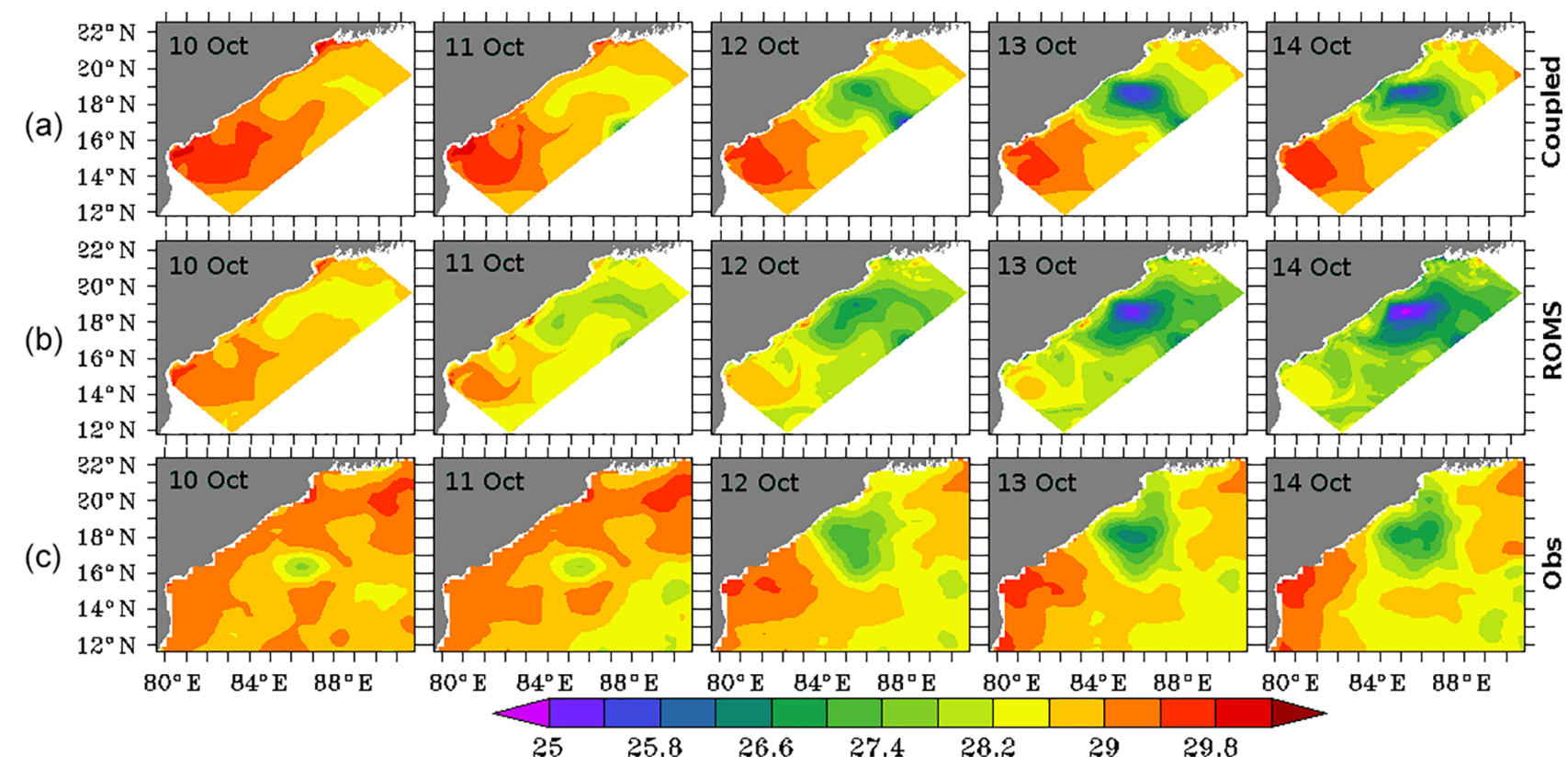

Figure 5. The daily averaged sea surface temperature (SST) in ${ }^{\circ} \mathrm{C}$ simulated by the coupled model (a) and stand-alone ROMS model (b) and observed from AVHRR sensor on the satellite (c).

alone ROMS model. Figure 5 shows that the coupled model captures the SST spatial pattern reasonably well with about $-0.5^{\circ} \mathrm{C}$ bias in northwestern $\mathrm{BoB}$ on $13-14$ October. This order of bias in SST could result from the errors in initial and boundary conditions provided for the model. The maximum cooling of the sea surface was observed on 13 October in the northwestern BoB in both the coupled model and observations. This post-cyclone cooling is primarily associated with the cyclone-induced upwelling resulting from the surface divergence driven by the Ekman transport. Thus, the coupled model reproduces dynamical processes and vertical velocities reasonably well. The stand-alone ROMS model overestimates the cyclone-induced cooling with a $-2.2{ }^{\circ} \mathrm{C}$ bias in SST on 13-14 October (Fig. 5). The stronger surface winds in the stand-alone WRF cause the larger cold bias in the stand-alone ROMS model.

\subsection{Cyclone-induced mixing}

The coupled atmosphere-ocean-wave simulation is an ideal tool to understand the air-sea exchange of fluxes and their effects on the oceanic water column. Surface wind sets up currents on the surface as well as initiating mixing in the interior of the upper ocean. In order to examine the strength of mixing due to Phailin, the model-simulated vertical temperature profile together with the surface wind speed, zonal and meridional components of the current, and kinetic energy at the on-track and off-track locations are plotted in Fig. 6. Comparatively stronger zonal and meridional currents were observed at the off-track location than the on-track location on 12 October. The larger kinetic energy available at the off- track location leads to greater mixing, resulting in a deeper mixed layer on 12 October compared to the on-track location. The surface wind speed at the on-track location shows typical temporal variation in a passing cyclone. The wind speed peaks, drops, and attains a second peak as the cyclone approaches, crosses over, and departs the location. The surface currents forced by these large variations in wind speed and direction at the on-track location result in a comparatively weaker magnitude than the off-track location.

The thermocline, defined as the depth of maximum temperature gradient, is usually given with reference to the location-dependent isotherm depth (Kessler, 1990; Wang et al., 2000). Over the BoB region, the depth of the $23^{\circ} \mathrm{C}$ isotherm (D23) was found to be an appropriate representative depth of the thermocline (Girishkumar et al., 2013). Based on the density criteria, we calculated the oceanic mixed layer depth (MLD) as the depth where density increased by $0.125 \mathrm{~kg} \mathrm{~m}^{-3}$ from its surface value. The inertial mixing introduced by the cyclone plays a central role in the deepening of D23 and MLD on 12 October 2013. The warmer nearsurface waters mixed downward when the cyclone crossed over this location. After the passage of cyclone, shoaling of D23 and MLD has observed as a consequence of cycloneinduced upwelling that entrained colder waters from the thermocline into the mixed layer. The temperature of the upper surface water $(25-30 \mathrm{~m})$ decreased by $3.5^{\circ} \mathrm{C}$ from its maximum value of $28^{\circ} \mathrm{C}$ after the landfall of the cyclone on 12-13 October at the off-track location (Fig. 6g). In response to the strong cyclonic winds, the D23 deepening by $40 \mathrm{~m}$ (from 50 to $90 \mathrm{~m}$ ) was observed during 04:00-12:00 GMT on $12 \mathrm{Oc}$ - 

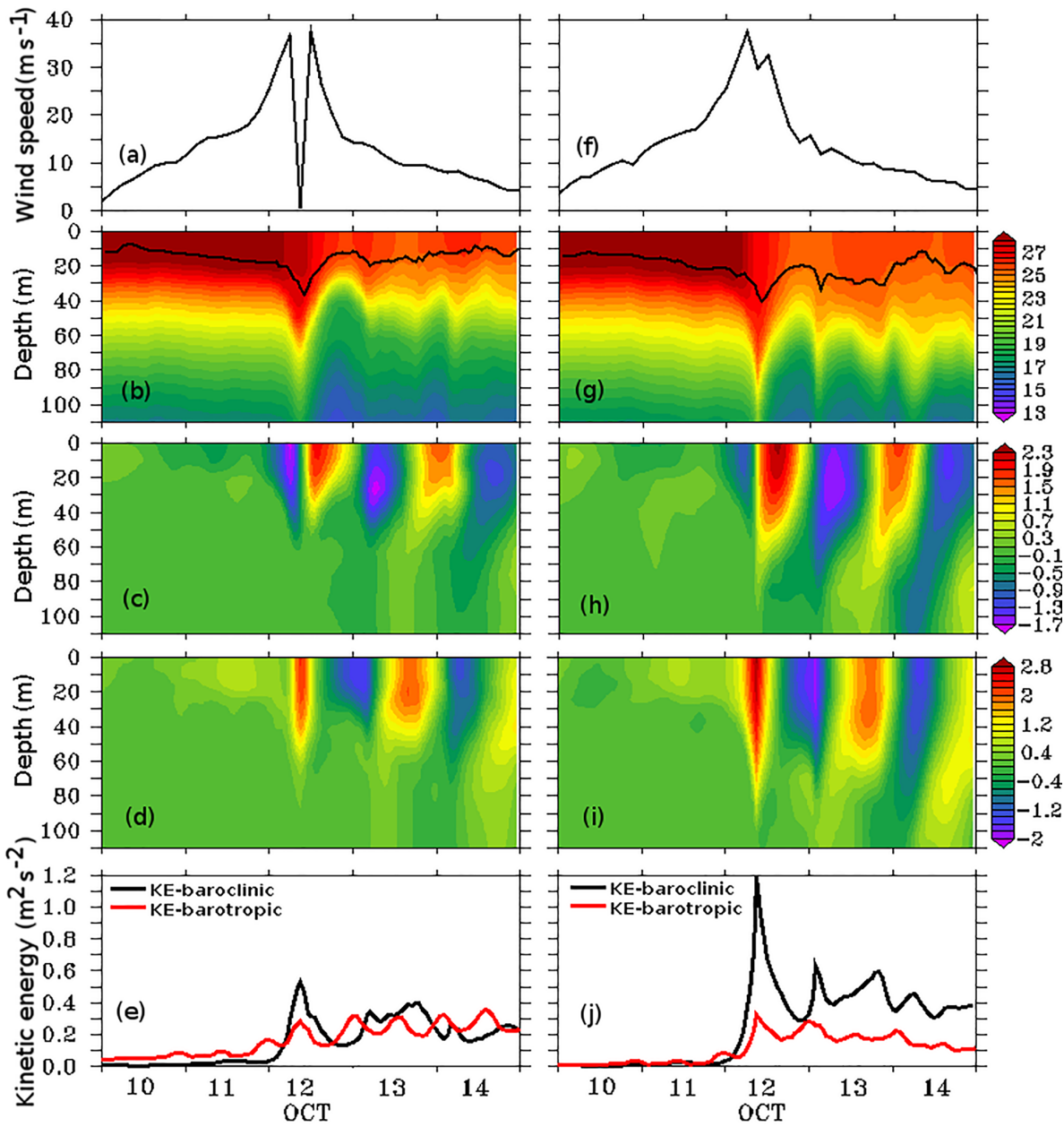

Figure 6. Coupled model-simulated and diagnosed variables at the on-track (left panel) and off-track (right panel) locations. (a, f) Surface wind speed $\left(\mathrm{m} \mathrm{s}^{-1}\right) ;(\mathbf{b}, \mathbf{g})$ temperature profile $\left({ }^{\circ} \mathrm{C}\right)$ and mixed layer depth (black line); $(\mathbf{c}, \mathbf{h}) u$-component of current $\left(\mathrm{m} \mathrm{s}{ }^{-1}\right) ;(\mathbf{d}, \mathbf{i})$ $v$-component of current $\left(\mathrm{m} \mathrm{s}^{-1}\right) ;(\mathbf{e}, \mathbf{j})$ kinetic energy of the baroclinic $\left(\mathrm{m}^{2} \mathrm{~s}^{-2}\right)$ and barotropic $\left(\times 10^{-2} \mathrm{~m}^{2} \mathrm{~s}^{-2}\right)$ current.

tober. At the same time, the MLD, denoted by a thick black line in Fig. 6g, deepens by about $15 \mathrm{~m}$. On the other hand, the on-track location showed cooling at the surface only for a short time on 13 October, and the deepening of D23 and MLD were 20 and $10 \mathrm{~m}$, respectively. To examine the role of cyclone-induced mixing in modulating the thermohaline structure of the upper ocean, we carried out further analysis on the coupled model simulations as discussed in the following sections.

\subsubsection{Kinetic energy distribution}

During the initial phase of Phailin, the zonal and meridional currents were primarily westward and southward, respectively (Fig. 6c, d, h, and i). However, on and after 12 October when the cyclone attained peak intensity and crossed over the location, alternative temporal sequences running westward/eastward in the zonal current and southward/northward in the meridional current were noticed in current profiles
(Fig. 6). The frequency of these reversals in zonal and meridional currents is recognized as a near-inertial frequency generated from the storm at these locations. The direction and magnitude of currents represent a variability that corresponds to the presence of near-inertial oscillations at the selected locations. The kinetic energy (KE) of currents at various depths is a proxy of energy available in the water column that becomes conducive to turbulent and inertial mixing. Time series of KE associated with the barotropic and depth-averaged baroclinic components of the current at the two point locations are illustrated in Fig. 6e (on-track) and 6j (off-track). The KE associated with the baroclinic component was found to be much higher than the barotropic component of current at both on-track and off-track locations. The depth-averaged baroclinic and barotropic current components' KE also depict the impinging oscillatory behavior. The peak magnitude of $\mathrm{KE}$ in baroclinic and barotropic currents at the off-track location was found to be $1.2 \mathrm{~m}^{2} \mathrm{~s}^{-2}$ and $0.3 \times 10^{-2} \mathrm{~m}^{2} \mathrm{~s}^{-2}$, respectively, on 12 October at 08:00 GMT, whereas the mag- 
nitude of KE in baroclinic and barotropic currents at the ontrack location was smaller than the off-track location during the peak intensity of the cyclone. The peak magnitude of kinetic energy in the baroclinic current at the off-track location was more than double that of on-track location. The comparatively smaller magnitude of $\mathrm{KE}$ at the on-track location could be associated with the rapid variations in wind speed and direction leading to the complex interaction between subsurface currents in the central region of the cyclone. It is worth noting that the time of peak KE in baroclinic currents coincides with the deepening of MLD and D23. Therefore, the KE generated in NIO is responsible for subsurface mixing that acts to deepen the mixed layer. The analysis suggests that energy available for the mixing process in the water column was mostly confined to the baroclinic currents at various depths.

\subsubsection{Primary frequency and depth of mixing}

The power spectrum analysis was performed on the time series profiles at the two selected locations to get a distribution of all frequencies operating in the mixing process during the passage of Phailin. The power spectrum analysis was performed on the zonal and meridional components of the baroclinic current profile and shown in Fig. 7. It is clear from the figure that the tidal (M2, the semidiurnal component of tide) and near-inertial oscillations (f) are the two dominant frequencies on the surface during cyclone Phailin. Under the influence of cyclonic winds, the NIO signal was stronger $\left(0.84 \mathrm{~m}^{2} \mathrm{~s}^{-2}\right)$ at the off-track than the on-track location. The depth penetration of NIO was up to 50 and $35 \mathrm{~m}$ at the offtrack and on-track location, respectively. The tidal frequency (M2) and inertial frequency (f) bands shown in Fig. 7 implies that the inertial oscillations were dominant over the tidal constituent in zonal and meridional baroclinic currents. At the off-track location, the largest power of the NIO was noticed at $14 \mathrm{~m}$ depth, but the tidal oscillations were almost absent in the vertical section of baroclinic current (Fig. 7). This finding motivated us to analyze the significance and distribution of this subsurface variability that resulted in an anomalous deepening of MLD. The highest power of this signal at the off-track location was associated within $0-15 \mathrm{~m}$, with a magnitude of $0.84 \mathrm{~m}^{2} \mathrm{~s}^{-1}$ in the zonal baroclinic current, and within $0-38 \mathrm{~m}$, with a magnitude of $0.76 \mathrm{~m}^{2} \mathrm{~s}^{-1}$ in the meridional baroclinic current. These signals, however, weakened with increasing depth and almost disappeared around $120 \mathrm{~m}$ depth. Compared to any other process, these NIOs were the strongest signals at the $14 \mathrm{~m}$ depth in the presence of local wind stress that dominated the mixing. Other processes include the background flows, the presence of eddies, variations in sea surface height, and nonlinear wave-wave and wave-current interactions (Guan et al., 2014; Park and Watts, 2005).

The second-order Butterworth filter was applied to the baroclinic current components to get the strength of NIO in

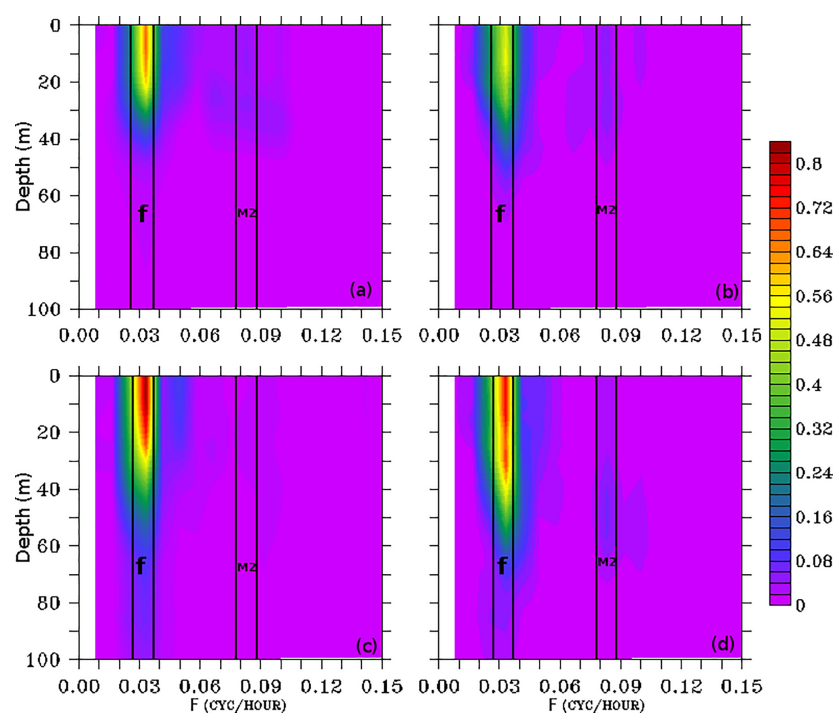

Figure 7. The power spectrum analysis $\left(\mathrm{m}^{2} \mathrm{~s}^{-1}\right)$ performed on the simulation period at the on-track (upper panel) and off-track (lower panel) locations for $(\mathbf{a}, \mathbf{c})$ the baroclinic zonal current and $(\mathbf{b}, \mathbf{d})$ the baroclinic meridional current.

the frequency range of 0.028 to 0.038 cycles $^{-1}$ at the selected locations. The filtered baroclinic current was further utilized to calculate the filtered inertial baroclinic $\operatorname{KE}\left(E_{\mathrm{f}}\right.$ in $\mathrm{m}^{2} \mathrm{~s}^{-2}$ ). The daily profiles of baroclinic KE were analyzed at the two selected locations and shown in Fig. 8. The peak baroclinic KE differs from $0.14 \mathrm{~m}^{2} \mathrm{~s}^{-2}$ at the on-track to $0.23 \mathrm{~m}^{2} \mathrm{~s}^{-2}$ at the off-track location on 12 October. As shown in Figs. 6 and 7, the filtered baroclinic KE profiles (Fig. 8) confirm the dominant presence of NIO at the off-track location compared to the on-track location. The decay of NIO with the increasing depth was noticed at both the locations. However, the NIO baroclinic KE penetrated up to $80 \mathrm{~m}$ in the case of an off-track location as compared to only $50 \mathrm{~m}$ at the on-track location. The analysis, therefore, suggests that the NIOs generated during Phailin were more energetic at the selected off-track location, which was also the location of maximum surface cooling as noted in Fig. 5. Therefore, the further analysis in the subsequent sections is limited to the off-track location only. To analyze the time distribution of the strong NIO, wavelet transform analysis was applied to the zonal and meridional baroclinic currents at $14 \mathrm{~m}$ depth. The scalogram, shown in Fig. 9, depicts the generation of NIO signal at the off-track location on 12 October that subsequently strengthened and attained its peak value in the middle of the day on 13 October. The energy percentage of the meridional component was always lower than the zonal component. The peak values of energy percentage were found in the time periods between 1 and 1.3 days. 

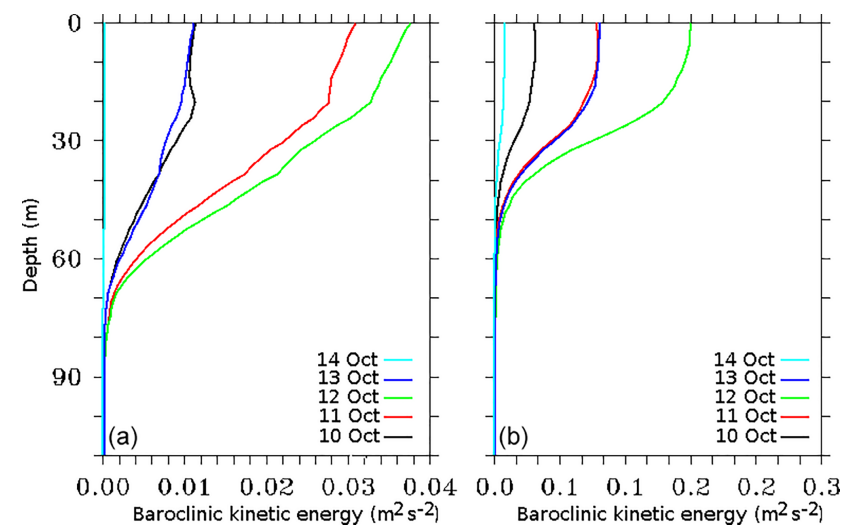

Figure 8. Daily averaged baroclinic kinetic energy $\left(\mathrm{m}^{2} \mathrm{~s}^{-2}\right)$ profile at the on-track (a) and off-track (b) locations as marked with stars in Fig. 2.

\subsubsection{Role of the downward propagation of energy}

To investigate the energy propagation from the surface to the interior layers of the upper ocean, we derived the rotary spectra (Gonella, 1972; Hayashi, 1979) of near-inertial wave numbers shown in Fig. 10. The daily averaged vertical wave-number rotary spectra provide a clear picture of wind energy distribution in the subsurface water. The anticyclonic spectrum $\left(A_{\mathrm{m}}\right)$ dominates the cyclonic spectra $\left(C_{\mathrm{m}}\right)$ for the entire duration of the cyclone. This feature indicates that the energy generated by these inertial oscillations propagates downward. The magnitude of these oscillations increased from the initial stage up to 12 October and remained at a high energy density for the rest of the cyclone period. This downward-directed energy initiated a process of mixing between the mixed layer and the thermocline. This energy helps to deepen the mixed layer against oceanic stratification by introducing a strong shear. The buoyancy of the stratified ocean was overcome to some extent by the shear generated, which assisted in the mixing process during the very severe cyclone. Alford and Gregg (2001) highlighted that in most of the cases, the energy of inertial oscillations potentially penetrates the mixed layer but suddenly drops as it touches the thermocline. The energy dissipation mechanism has been studied in a few other studies (Chant, 2001; Jacob and Shay, 2003). The two-layer model described by Burchard and Rippeth (2009) illustrated the process of the generation of sufficient shear to start mixing near the thermocline. Their simple model ignored the effect of the lateral density gradient, mixing, and advection. Burchard et al. (2009) mentioned four important parameters for shear generation, i.e., surface wind stress $\left(P_{\mathrm{S}} S^{2}\right)$, bed stress $\left(-D_{\mathrm{b}} S^{2}\right)$, interfacial stress $\left(-D_{I} S^{2}\right)$, and barotropic flow $\left(P_{\mathrm{m}} S^{2}\right)$. Utilizing simulations from our coupled atmosphere-ocean-wave model, we calculated individual terms as suggested by Burchard et al. (2009), and we present them in Fig. 11. Surface wind stress was found to be the most dominating term in modulat-

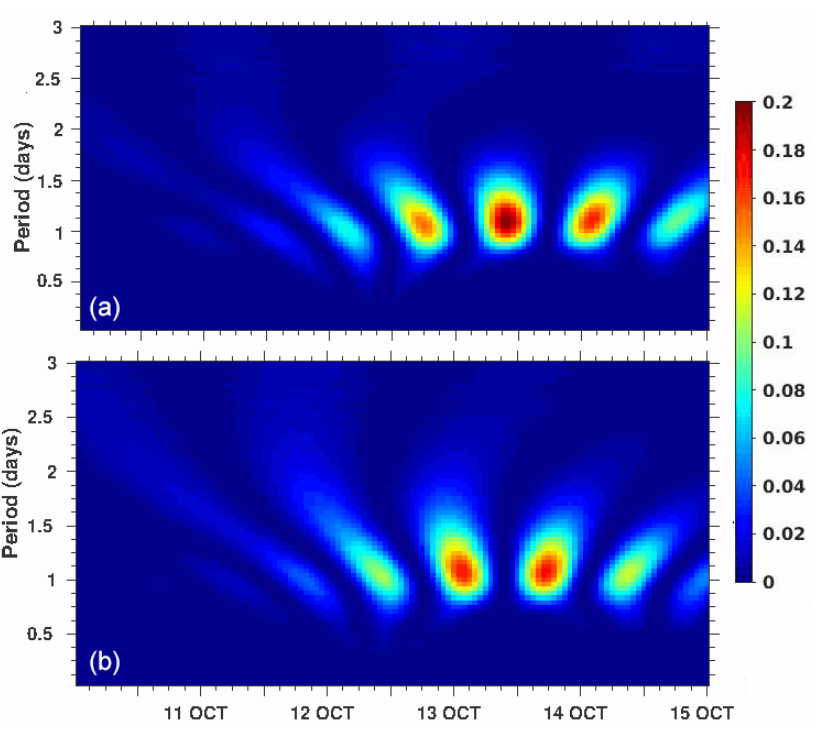

Figure 9. The scalogram by continuous wavelet transform (CWT) method in percentage at $14 \mathrm{~m}$ depth. Wavelet scalogram shown for the zonal baroclinic current (a) and for the meridional baroclinic current (b).

ing the magnitude of bulk shear during the stormy event. The rest of the terms were relatively weaker and, therefore, contributed only marginally to the variability in the bulk shear.

To examine the generation and dissipation of these inertial oscillations, the shear generated by the near-inertial baroclinic current $\left(S_{\mathrm{f}}^{2}\right)$ and turbulent kinetic energy dissipation rate $(\varepsilon)$ was calculated and analyzed. The shear produced by inertial oscillations increased at $20-80 \mathrm{~m}$ depth, and a higher magnitude was associated with the peak wind speed of the cyclone (Fig. 12a). This shear overcame the stratification (Fig. 12b), represented by buoyancy frequency $N^{2}$, and played important role in the mixing and deepening of the thermocline and mixed layer on 12 October. The value of the kinetic energy dissipation rate $(\varepsilon)$ increased from $4 \times 10^{-14}$ to $2.5 \times 10^{-13} \mathrm{~W} \mathrm{~kg}^{-1}$ on approaching the thermocline (Fig. 12c). The increase in $\varepsilon$ indicates the weakening of the shear generated by the inertial waves leading to the fast disappearance of these baroclinic instabilities from the region. The nonlinear interaction between the NIO and internal tides together with the prevailing background currents causes the rapid dissipation of kinetic energy in the thermocline. Guan et al. (2014) also reported an accelerated dampening of NIO associated with the wave-wave interactions between NIO and internal tides. The background currents were found to modify the propagation of NIO (Park and Watts, 2005). The magnitude of the turbulent eddy diffusivity $\left(K_{\rho}\right)$, shown in Fig. 12d, implies that the greater mixing takes place within the mixed layer where $K_{\rho}$ was high $\left(6.3 \times 10^{-11}\right.$ to $\left.1.2 \times 10^{-11} \mathrm{~m}^{2} \mathrm{~s}^{-1}\right)$. The daily averaged values of $\varepsilon$ and $K_{\rho}$ were $1.2 \times 10^{-13} \mathrm{~W} \mathrm{~kg}^{-1}$ and $1.5 \times 10^{-10} \mathrm{~m}^{2} \mathrm{~s}^{-1}$, respectively, on 12 October, which were higher compared to the 


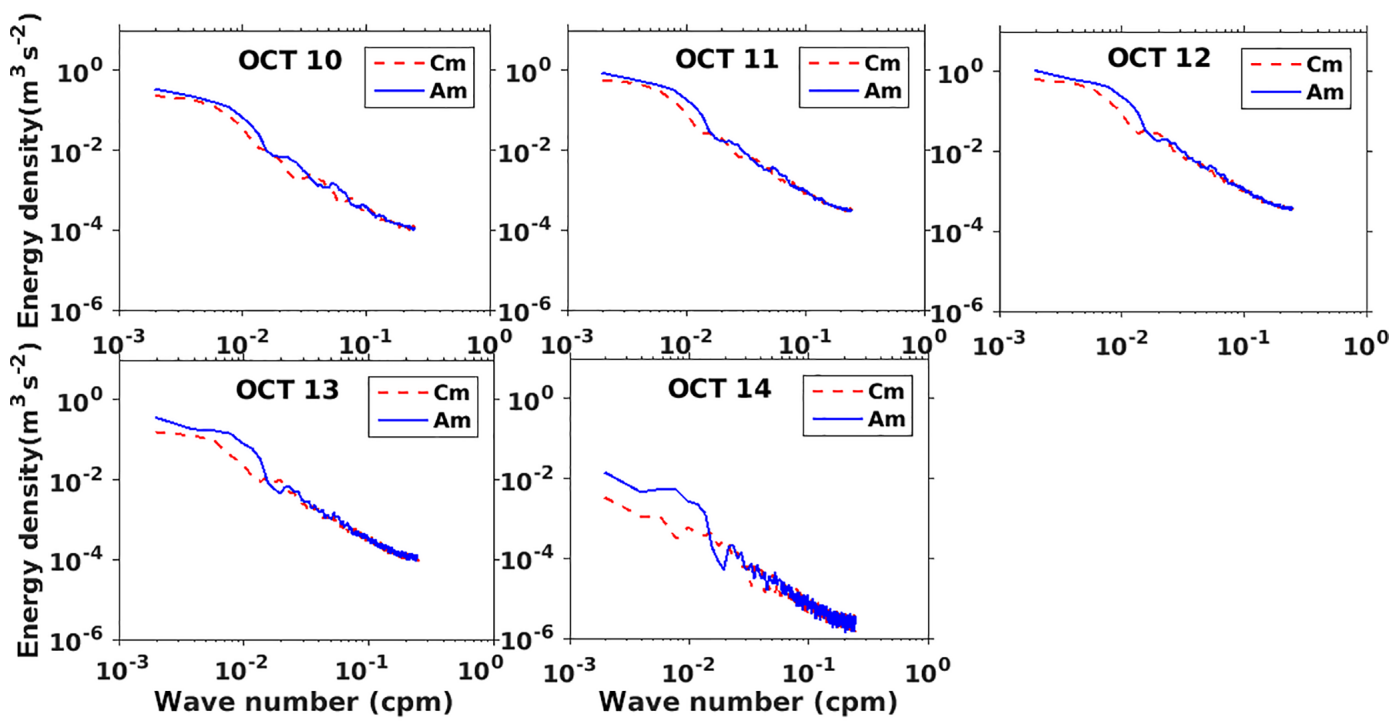

Figure 10. The daily averaged vertical wave-number rotary spectra of near-inertial oscillations. The anticyclonic and cyclonic spectra are represented by blue and dotted red lines, respectively.

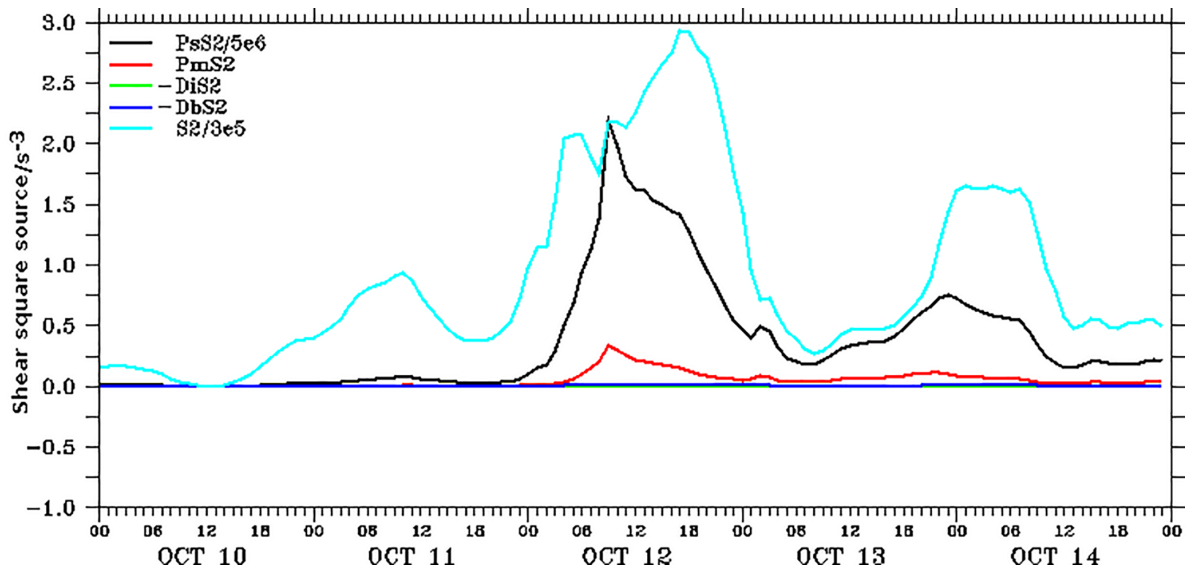

Figure 11. The model-simulated bulk properties at the selected point location. The vertical shear square axis is multiplied by a factor of $10^{-6}$. The magnitude of bulk shear squared $S^{2}$ (cyan color), surface wind stress $P_{\mathrm{s}} S^{2}$ (black color), barotropic effect $P_{\mathrm{m}} S^{2}$ (red color), bottom stress $-D_{\mathrm{b}} S^{2}$ (blue color), and interfacial friction $-D_{\mathrm{i}} S^{2}$ (green color) are shown for the duration of the cyclone.

initial 2 days of the cyclonic event. Results from the present study, as well as conclusions from past studies, indicate that wave-current interaction, mesoscale processes, and wavewave interaction can affect the process of downward mixing and cause the dissipation of inertial oscillations.

\section{Conclusions}

Processes controlling the subsurface mixing were evaluated under the high wind speed regime of the severe cyclonic storm Phailin over the BoB. A coupled atmosphereocean-wave (WRF+ROMS+SWAN) model as part of the COAWST modeling system was used to simulate atmospheric and oceanic conditions during the passage of the
Phailin cyclone. A detailed analysis of model-simulated data revealed interesting features of generation, propagation, and dissipation of kinetic energy in the upper-oceanic water column. The deepening of the MLD and thermocline by 15 and $40 \mathrm{~m}$, respectively, was explained through the strong shear generated by the inertial oscillations that helped to overcome the stratification and initiate mixing at the base of the mixed layer. However, there was a rapid dissipation of the shear with increasing depth below the thermocline. The peak magnitude of kinetic energy in baroclinic and barotropic currents was found to be 1.2 and $0.3 \times 10^{-2} \mathrm{~m}^{2} \mathrm{~s}^{-2}$, respectively. The power spectrum analysis suggested a dominant frequency operative in subsurface mixing that was associated with nearinertial oscillations. The peak strength of $0.84 \mathrm{~m}^{2} \mathrm{~s}^{-1}$ in the 

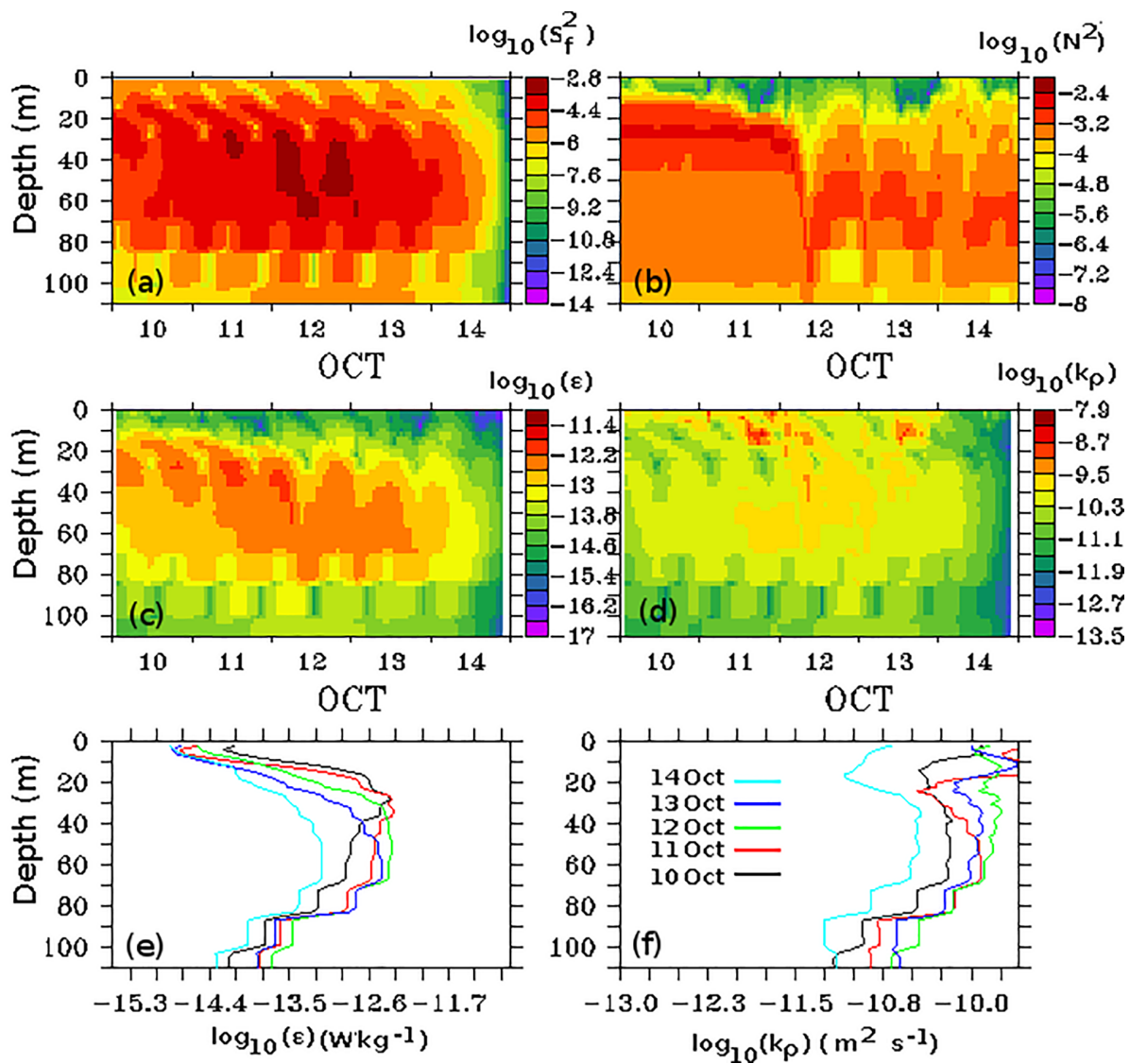

Figure 12. Profiles of (a) velocity shear $\log _{10}\left(S^{2}\right)$, (b) buoyancy frequency $\log _{10}\left(N^{2}\right)$, (c) turbulent kinetic energy dissipation rate $\log _{10}$ $(\varepsilon)$, and (d) turbulent eddy diffusivity $\log _{10}\left(K_{\rho}\right)$; (e) and (f) are daily averaged turbulent kinetic energy dissipation rate and turbulent eddy diffusivity, respectively.

zonal baroclinic current was found at $14 \mathrm{~m}$ depth at a location in the northwestern BoB. The baroclinic kinetic energy remained higher $\left(>0.03 \mathrm{~m}^{2} \mathrm{~s}^{-2}\right)$ during $11-12$ October and decreased rapidly after that. The wave-number rotary spectra identified the downward propagation, from the surface up to the thermocline, of energy generated by inertial oscillations. A quantitative analysis of shear generated by the near-inertial baroclinic current showed higher shear generation at $20-80 \mathrm{~m}$ depth during peak surface winds. Analysis highlights that greater mixing within the mixed layer takes place where the eddy kinetic diffusivity is high $\left(>6 \times 10^{-11} \mathrm{~m}^{2} \mathrm{~s}^{-1}\right)$. The turbulent kinetic energy dissipation rate increased from $4 \times 10^{-14}$ to $2.5 \times 10^{-13} \mathrm{~W} \mathrm{~kg}^{-1}$ on approaching the thermocline, which dampened the mixing process further down into the thermocline layer. The wavecurrent interaction, mesoscale processes, and wave-wave interaction increased the dissipation rate of shear and, thereby, limited the downward mixing up to the thermocline. The coupled model was found to be a useful tool to investigate airsea interaction, kinetic energy propagation, and mixing in the upper ocean. The results from this study highlight the importance of atmosphere-ocean coupling for a better understand- ing of the oceanic response under strong wind conditions. The proper representation of kinetic energy propagation and oceanic mixing have applications in improving the intensity prediction of a cyclone, storm surge forecasting, and biological productivity.

Data availability. The atmospheric and ocean model forcing data can be obtained from FNL (https://rda.ucar.edu/datasets/ds083.2/; NCEPFNL, 2000) and ECCO2 (https://ecco.jpl.nasa.gov/products/ all/, last access: October 2016), respectively. The observation data utilized for model validation are obtained from Indian $\mathrm{Na}$ tional Centre for Ocean Information Services (http://www.incois. gov.in/portal/index.jsp, last access: February 2017). The model simulations used for the research article can be obtained from the first author, Kumar Ravi Prakash, by sending an email to kravi1220@gmail.com.

Author contributions. KRP and TN performed model simulations and analyzed data. VP prepared the manuscript with contributions from all co-authors. 
Competing interests. The authors declare that they have no conflict of interest.

Acknowledgements. ECCO2 is a contribution to the NASA Modeling, Analysis, and Prediction (MAP) program. The study benefitted from the funding support from the Ministry of Earth Sciences, Government of India, and the Space Applications Centre, Indian Space Research Organisation. The high-performance computing (HPC) facility provided by IIT Delhi and the Department of Science and Technology (DST-FIST 2014 at CAS), Government of India, are thankfully acknowledged. Authors are thankful to Lingling Xie for his productive suggestions. Graphics were generated in this paper using Ferret and NCL. The constructive comments from three anonymous reviewers helped to improve the paper. Tanuja Nigam and Kumar Ravi Prakash acknowledge MoES and UGC-CSIR, respectively, for their PhD fellowship support.

Edited by: Markus Meier

Reviewed by: three anonymous referees

\section{References}

Alam, M. M., Hossain, M. A., and Shafee, S.: Frequency of Bay of Bengal cyclonic storms and depressions crossing different coastal zones, Int. J. Climatol., 23, 1119-1125, https://doi.org/10.1002/joc.927, 2003.

Alford, M. H. and Gregg, M. C.: Near-inertial mixing: modulation of shear, strain and microstructure at low latitude, J. Geophys. Res., 106, 16947-16968, 2001.

Auger, F. and Flandrin, P.: Improving the Readability of TimeFrequency and Time-Scale Representations by the Reassignment Method, IEEE Transactions on Signal Processing, 43, 10681089, 1995.

Booij, N., Ris, R. C., and Holthuijsen, L. H.: A thirdgeneration wave model for coastal regions, Part I, Model description and validation, J. Geophys. Res., 104, 7649-7666, https://doi.org/10.1029/98JC02622, 1999.

Burchard, H. and Rippeth, T. P.: Generation of bulk shear spikes in shallow stratified tidal seas, J. Phys. Oceanogr., 39, 969-985, 2009.

Chang, S. W. and Anthes, F. A.: The mutual response of the tropical cyclone and the ocean, J. Phys. Oceanogr., 9, 128-135, 1979.

Chant, R. J.: Evolution of near-inertial waves during an upwelling event on the New Jersey Inner Shelf, J. Phys. Oceanogr., 31, 746764, 2001.

Chassignet, E. P., Arango, H. G., Dietrich, D., Ezer, T., Ghil, M., Haidvogel, D. B., Ma, C. C., Mehra, A., Paiva, A. M., and Sirkes, Z.: DAMEE-NAB: the base experiments. Dyn. Atmos. Oceans, 32, 155-183, 2000.

Chen, S., Chen, D., and Xing, J.: A study on some basic features of inertial oscillations and near-inertial internal waves, Ocean Sci., 13, 829-836, https://doi.org/10.5194/os-13-829-2017, 2017.

Cione, J. J. and Uhlhorn, E. W.: Sea surface temperature variability in hurricanes: Implications with respect to intensity change, Mon. Weather Rev., 131, 1783-1796, https://doi.org/10.1175//2562.1, 2003.
Dudhia, J.: Numerical study of convection observed during the winter monsoon experiment using a mesoscale two dimensional model, J. Atmos. Sci., 46, 3077-3107, 1989.

Gill, A. E.: On the behavior of internal waves in the wake of storms, J. Phys. Oceanogr., 14, 1129-1151, 1984.

Girishkumar, M. S., Ravichandran, M., and Han, W.: Observed intraseasonal thermocline variability in the Bay of Bengal, J. Geophys. Res.-Oceans, 118, 3336-3349, https://doi.org/10.1002/jgrc.20245, 2013.

Gonella, J.: A study of inertial oscillations in the upper layers of the oceans, Deep-Sea Res., 18, 775-788, 1971.

Gonella, J.: A rotary-component method for analysing meteorological and oceanographic vector time series, Deep-Sea Res., 19, 833-846, 1972.

Gröger, M., Dieterich, C., Meier, H. E. M., and Schimanke, S.: Thermal air-sea coupling in hindcast simulations for the North Sea and Baltic Sea on the NW European shelf, Tellus A, 67, 26911, https://doi.org/10.3402/tellusa.v67.26911, 2015.

Guan, S., Zhao, W., Huthnance, J. Tian, J., and Wang, J.: Observed upper ocean response to typhoon Megi (2010) in the Northern South China Sea, J. Geophys. Res.-Oceans, 119, 3134-3157, https://doi.org/10.1002/2013JC009661, 2014.

Haidvogel, D. B., Arango, H. G., Hedstrom, K., Beckmann, A., Malanotte-Rizzoli, P., and Shchepetkin, A. F.: Model evaluation experiments in the North Atlantic Basin: Simulations in nonlinear terrain-following coordinates, Dyn. Atmos. Oceans, 32, 239281, 2000.

Haidvogel, D. B., Arango, H. G., Budgell, W. P., Cornuelle, B. D., Curchitser, E., Di Lorenzo, E., Fennel, K., Geyer, W. R., Hermann, A. J., Lanerolle, L., Levin, J., McWilliams, J. C., Miller, A. J., Moore, A. M., Powell, T. M., Shchepetkin, A. F., Sherwood, C. R., Signell, R. P., Warner, J. C., and Wilkin, J.: Regional ocean forecasting in terrain-following coordinates: model formulation and skill assessment, J. Comput. Phys., 227, 3595-3624, 2008.

Hayashi, Y.: Space-time spectral analysis of rotary vector series, J. Atmos. Sci., 36, 757-766, 1979.

Ho-Hagemann, H. T. M., Gröger, M., Rockel, B., Zahn, M., Geyer, B., and Meier, H. E. M: Effects of air-sea coupling over the North Sea and the Baltic Sea on simulated summer precipitation over Central Europe, Clim. Dyn., 49, 3851, https://doi.org/10.1007/s00382-017-3546-8, 2017.

Hong, S. Y. and Lim, J. O. J.: The WRF single-moment 6-class microphysics scheme (WSM6), J. Korean Meteor. Soc., 42, 129151, 2006.

IMD Report: Very Severe Cyclonic Storm, PHAILIN over the Bay of Bengal (08-14 October 2013) A Report, India Meteorological Department, Technical Report, October 2013.

Jacob, S. D. and Shay, L. K.: The role of oceanic mesoscale features on the tropical cyclone-induced mixed layer response: A case study, J. Phys. Oceanog., 33, 649-676, 2003.

Jacob, R., Larson, J., and Ong, E.: M x N Communication and Parallel Interpolation in CCSM Using the Model Coupling Toolkit, Preprint ANL/MCSP1225-0205, Mathematics and Computer Science Division, Argonne National Laboratory, 25 pp., 2005.

Jeworrek, J., Wu, L., Dieterich, C., and Rutgersson, A.: Characteristics of convective snow bands along the Swedish east coast, Earth Syst. Dynam., 8, 163-175, https://doi.org/10.5194/esd-8163-2017, 2017. 
Johnston, T. M. S., Chaudhuri, D., Mathur, M., Rudnick, D. L., Sengupta, D., Simmons, H. L., Tandon, A., and Venkatesan, R.: Decay mechanisms of near-inertial mixed layer oscillations in the Bay of Bengal, Oceanography, 29, 180-191, https://doi.org/10.5670/oceanog.2016.50, 2016.

Kain, J. S.: The Kain-Fritsch convective parameterization: An update, J. Appl. Meteor., 43, 170-181, 2004.

Kessler, W. S.: Observations of long Rossby waves in the northern tropical Pacific, J. Geophys. Res., 95, 5183-5217, 1990.

Kirby, J. T. and Chen, T. M.: Surface waves on vertically sheared flows Approximate dispersion relations, J. Geophys. Res., 94, 1013-1027, https://doi.org/10.1029/JC094iC01p01013, 1989.

Komen, G. J., Hasselmann, S., and Hasselmann, K.: On the existence of a fully developed wind-sea spectrum, J. Phys. Oceanogr., 14, 1271-1285, 1984.

Larson, J., Jacob, R., and Ong, E.: The Model Coupling Toolkit: A New Fortran90 Toolkit for Building Multiphysics Parallel Coupled Models, Preprint ANL/MCS- P1208-1204, Mathematics and Computer Science Division, Argonne National Laboratory, 25 pp., 2004.

Leipper, D. F.: Observed Ocean Conditions and Hurricane Hilda, 1964, J. Atmos. Sci., 24, 182-186, https://doi.org/10.1175/15200469(1967)024<0182:OOCAHH>2.0.CO;2, 1967.

Li, Z., Yu, W., Li, T., Murty, V. S. N., and Tangang, F.: Bimodal character of cyclone climatology in the Bay of Bengal modulated by monsoon seasonal cycle, J. Climate, 26, 1033-1046, https://doi.org/10.1175/JCLI-D-11-00627.1, 2013.

Lilly, J. M. and Olhede, S. C.: Generalized Morse Wavelets as a Superfamily of Analytic Wavelets, IEEE Transactions on Signal Processing, 60, 6036-6041, 2012.

Longshore, D.: Encyclopedia of Hurricanes, Typhoons, and Cyclones, 468 pp., Checkmark, New York, 2008.

Lukas, R. and Lindstrom, E.: The mixed layer of the western equatorial Pacific Ocean, J. Geophys. Res., 96, 3343-3357, 1991.

MacKinnon, J. A. and Gregg, M. C.: Spring Mixing: Turbulence and Internal Waves during Restratification on the New England Shelf, J. Phys. Oceanogr., 12, 2425-2443 2005.

Mandal, M., Singh, K. S., Balaji, M., and Mohapatra, M.: Performance of WRF-ARW model in real-time prediction of Bay of Bengal cyclone 'Phailin', Pure Appl. Geophys., 173, https://doi.org/10.1007/s00024-015-1206-7, 2015.

Menenenlis, D., Hill, C., Adcroft, A., Campin, J.-M., Cheng, B., Clottl, B., Fukumori, I., Pheimbach, C., Henze, A., Kohl, T., Lee, D., Stammer, J., Taft, and Zhang, J.: NASA supercomputer improves prospects for ocean climate research, Eos Trans. AGU, 86, 89-96, https://doi.org/10.1029/2005EO090002, 2005.

Monin, A. S. and Obukhov, A. M. F.: Basic laws of turbulent mixing in the surface layer of the atmosphere, Contrib. Geophys. Inst. Acad. Sci. USSR, 151, e187, 1954.

National Centers for Environmental Prediction/National Weather Service/NOAA/U.S. (NCEPFNL): Department of Commerce, NCEP FNL Operational Model Global Tropospheric Analyses, continuing from July 1999, Research Data Archive at the National Center for Atmospheric Research, Computational and Information Systems Laboratory, data set, available at: https://doi.org/10.5065/D6M043C6 (last access: 4 July 2015), 2000.

National Geophysical Data Center: 2-minute Gridded Global Relief Data (ETOPO2) v2. National Geophysical Data Center, NOAA, available at: https://doi.org/10.7289/V5J1012Q (last access: July 2015), 2006

Neetu, S., Lengaigne, M., Vincent, E. M., Vialard, J., Madec, G., Samson, G., Ramesh Kumar, M. R., and Durand, F.: Influence of upper-ocean stratification on tropical cyclone-induced surface cooling in the Bay of Bengal, J. Geophys. Res., 117, C12020, https://doi.org/10.1029/2012JC008433, 2012.

Noh, Y., Cheon, W. G., Hong, S. Y., and Raasch, S.: Improvement of the K-profile model for the planetary boundary layer based on large eddy simulation data, Bound. Layer Meteor., 107, 401-427, 2003.

Osborn, T. R.: Estimates of the Local-Rate of Vertical Diffusion from Dissipation Measurements, J. Phys. Oceanogr., 10, 83-89, 1980.

Palmer, M. R., Rippeth, T. P., and Simpson, J. H.: An investigation of internal mixing in a seasonally stratified shelf sea, J. Geophys Res., 113, C12005, https://doi.org/10.1029/2007JC004531, 2008.

Pant, V., Girishkumar, M. S., Udaya Bhaskar, T. V. S., Ravichandran, M., Papa, F., and Thangaprakash, V. P.: Observed interannual variability of near-surface salinity in the Bay of Bengal, $\mathrm{J}$ Geophys. Res., 120, 3315-3329, 2015.

Park, J. H. and Watts, D. R.: Near-inertial oscillations interacting with mesoscale circulation in the southwestern Japan/East Sea, Geophys. Res. Lett., 32, L10611, https://doi.org/10.1029/2005GL022936, 2005.

Prakash, K. R. and Pant, V: Upper oceanic response to tropical cyclone Phailin in the Bay of Bengal using a coupled atmosphere-ocean model, Ocean Dynam., 67, 51-64, https://doi.org/10.1007/s10236-016-1020-5, 2017.

Price, J. F.: Upper ocean response to a hurricane, J. Phys. Oceanog., 11, 153-175, 1981.

Price, J. F., Mooers, C. N., and Van Leer, J. C.: Observation and simulation of storm-induced mixed-layer deepening, J. Phys. Oceanogr., 8, 582-599,

doi10.1175/1520-0485(1978)008<0582:OASOSI >2.0.CO;2, 1978.

Pugh, D. T.: Tides, Surges and Mean Sea-Level, John Wiley \& Sons, Chichester, 472 pp., 1987.

Rao, R. R. and Sivakumar, R.: Seasonal variability of sea surface salinity and salt budget of the mixed layer of the north Indian Ocean, J. Geophys. Res., 108, 3009, https://doi.org/10.1029/2001JC000907, 2003.

Sanford, T. B., Black, P. G., Haustein, J., Feeney, J. W., Forristall, G. Z., and Price, J. F.: Ocean response to a hurricane. Part I: Observations, J. Phys. Oceanogr., 17, 2065-2083, 1987.

Sanil Kumar, V. and Anjali Nair, M.: Inter-annual variations in wave spectral characteristics at a location off the central west coast of India, Ann. Geophys., 33, 159-167, https://doi.org/10.5194/angeo-33-159-2015, 2015.

Schahinger, R. B.: Near inertial motion on the south Australian shelf, J. Phys. Oceanogr., 18, 492-504, 1988.

Shay, L. K. and Elsberry, R. L.: Vertical structure of the ocean current response to a hurricane, J. Phys. Oceanog., 19, 649-669, 1989.

Shay, L. K., Black, P., Mariano, A., Hawkins, J., and Elsberry, R.: Upper ocean response to hurricane Gilbert, J. Geophys. Res., 97, 227-248, 1992. 
Shay, L. K., Goni, G. J., and Black, P. G.: Effects of a warm oceanic feature on Hurricane Opal, Mon. Weather Rev., 128, 1366-1383, https://doi.org/10.1175/15200493(2000)128<1366:EOAWOF>2.0.CO;2, 2000.

Shchepetkinand A. F. and McWilliams J. C.: The Regional Ocean Modeling System: A split-explicit, free-surface, topography following coordinates ocean model, Ocean Modell., 9, 347-404, 2005.

Shearman, R. K.: Observations of near-inertial current variability on the New England shelf, J. Geophys. Res., 110, C02012, https://doi.org/10.1029/2004JC002341, 2005.

Skamarock, W. C., Klemp, J. B., Dudhia, J., Gill, D. O., Barker, D. M., Wang, W., and Powers, J. G.: A Description of the Advanced Research WRF Version 2, NCAR Technical Note, NCAR/TN468+STR., 2005.

Srinivas, C. V., Mohan, G. M., Naidu, C. V., Baskaran, R., and Venkatraman, B.: Impact of air-sea coupling on the simulation of tropical cyclones in the North Indian Ocean using a simple 3D ocean model coupled to ARW, J. Geophys. Res.-Atmos., 121, 9400, https://doi.org/10.1002/2015JD024431, 2016.

Camargo, S. J., Sobel, A. H., Barnston, A. G., and Emanuel, K. A.: Tropical cyclone genesis potential index in climate models, Tellus A, 59, 428-443, 2007.

Taylor, P. K. and Yelland, M. J.: The dependence of sea surface roughness on the height and steepness of the waves, J. Phys. Oceanogr., 31, 572-590, 2001.

Thadathil, P., Muraleedharan, P. M., Rao, R. R., Somayajulu, Y. K., Reddy, G. V., and Revichandran, C.: Observed seasonal variability of barrier layer in the Bay of Bengal, J. Geophys. Res., 112, C02009, https://doi.org/10.1029/2006JC003651, 2007.

van der Lee, E. M. and Umlauf, L.: Internal wave mixing in the Baltic Sea: near-inertial waves in the absence of tides, J. Geophys. Res., 116, C10016, https://doi.org/10.1029/2011JC007072, 2011.

Varkey, M. J., Murty, V. S. N., and Suryanarayana, A.: Physical oceanography of the Bay of Bengal and Andaman Sea, Oceanogr. Mar. Biol., 34, 1-70, 1996.
Vinayachandran, P. N., Murty, V. S. N., and Ramesh Babu, V.: Observations of barrier layer formation in the Bay of Bengal during summer monsoon, J. Geophys. Res., 107, 8018, https://doi.org/10.1029/2001JC000831, 2002.

Vissa, N. K., Satyanarayana, A. N. V., and Prasad Kumar, B.: Intensity of tropical cyclones during pre- and postmonsoon seasons in relation to accumulated tropical cyclone heat potential over Bay of Bengal, Nat. Hazards, 68, 351, https://doi.org/10.1007/s11069-013-0625-y, 2013.

Wang, B., Wu, R., and Lukas, R.: Annual adjustment of the thermocline in the tropical Pacific Ocean, J. Clim., 13, 596-616, 2000.

Warner, J. C., Sherwood, C. R., Arango, H. G., and Signell, R. P.: Performance of four turbulence closure models implemented using a generic length scale method, Ocean Modell., 8, 81-113, https://doi.org/10.1016/j.ocemod.2003.12.003, 2005.

Warner, J. C., Armstrong, B., He, R., and Zambon, J. B.: Development of a coupled ocean-atmosphere-wave-sediment transport (COAWST) modeling system, Ocean Modell., 35, 230-244, https://doi.org/10.1016/j.ocemod.2010.07.010, 2010.

Wu, C.-C., Tu, W.-T., Pun, I.-F., Lin, I.-I., and Peng, M. S.: Tropical cyclone-ocean interaction in Typhoon Megi (2010) - A synergy study based on ITOP observations and atmosphere-ocean coupled model simulations, J. Geophys. Res.-Atmos., 121, 153-167, https://doi.org/10.1002/2015JD024198, 2016.

Yanase, W., Satosh, M., Taniguchi, H., and Fujinami, H.: Seasonal and Intraseasonal Modulation of tropical cyclogenesis environment over the Bay of Bengal during the extended summer monsoon, J. Climate, 25, 2914-2930, https://doi.org/10.1175/JCLID-11-00208.1, 2012.

Zambon J. B., He, R., and Warner, J. C.: Investigation of hurricane Ivan using the coupled ocean-atmosphere-wave-sediment transport (COAWST) model, Ocean Dyn., 64, 1535-1554, https://doi.org/10.1007/s10236-014-0777-7, 2014.

Zhang, S., Xie, L., Hou, Y., Zhao, H., Qi, Y., and Yi, X.: Tropical storm-induced turbulent mixing and chlorophyll-a enhancement in the continental shelf southeast of Hainan Island, J. Mar. Syst., 129, 405-414, 2014. 